Hassan et al., J Nutr Disorders Ther 2016, 6:2 DOI: 10.4172/2161-0509.1000190

\title{
Antimicrobial Activity of Cinnamomum tamala Leaves
}

\author{
Waseem Hassan ${ }^{1 *}$, Syeda Nida Zainab Kazmi ${ }^{2}$, Hamsa Noreen ${ }^{1}$, Ali Riaz ${ }^{2}$ and Bakht Zaman ${ }^{1}$ \\ ${ }^{1}$ Institute of Chemical Sciences, University of Peshawar, Peshawar -25120, Khyber Pakhtunkhwa, Pakistan \\ ${ }^{2}$ Department of Chemistry, Sarhad University of Science and Information Technology, Peshawar, Pakistan \\ *Corresponding author: Waseem Hassan, Institute of Chemical Sciences, University of Peshawar, Peshawar -25120, Khyber Pakhtunkhwa, Pakistan, Tel: \\ 0092-91-9216652; E-mail: waseem_anw@yahoo.com
}

Rec date: May 05, 2016; Acc date: June 06, 2016; Pub date: June 13, 2016

Copyright: $\odot 2016$ Hassan W et al. This is an open-access article distributed under the terms of the Creative Commons Attribution License, which permits unrestricted use, distribution, and reproduction in any medium, provided the original author and source are credited.

\begin{abstract}
In the present study phytochemical constituents, elemental composition and antimicrobial potential of the crude methanolic extract of Cinnamomum tamala leaves were explored. Tannins, alkaloids, flavonoids and terpenoids were detected as major phytochemical constituents. $\mathrm{Cd}, \mathrm{Mn}, \mathrm{Pb}, \mathrm{Cr}, \mathrm{Sb}, \mathrm{Na}, \mathrm{K}, \mathrm{Ca}, \mathrm{Cu}$ and Fe concentration were determined by atomic absorption spectroscopy spectrometry (AAS). The results confirmed the presence of Ca as major metallic content i.e. $5634.25 \mathrm{mg} / \mathrm{kg}$. The concentration of other heavy metals particularly $\mathrm{Fe}$ and $\mathrm{Na}$ were higher as compared to other metals while $\mathrm{Cd}$ was not detected. Antimicrobial potential of the crude extract and its fractions i.e. aqueous, n-hexane, dichloromethane and isobutanol were tested against six gram-negative, three gram-positive bacterial strains and one fungal strain by agar well diffusion method. The evaluated extracts evaluated showed variedable degree of inhibition zones against all tested microbes except dichloromethane, aqueous fraction and crude extract which were completely inactive against Salmonella typhi (a gram negative strain). The screening suggests that Cinnamomum tamala have interesting therapeutic potential and of course further biochemical tests are required to explore its possible mechanism of action.
\end{abstract}

Keywords: Phytochemicals; Heavy metals; Antibacterial activity

\section{Introduction}

Therapeutic properties of various plants have been used to treat human diseases for centuries. The medicinal value of these plants is due to the presence of certain chemical substances scientifically known as phytochemicals that generate definite physiological action on the human body [1]. Phytochemicals are natural bioactive compounds occurring in plants that work with nutrients and fibers to act or protect against diseases. These natural products are the secondary metabolites that are taxonomically extremely diverse in nature forming the source of new drugs based on their modes of pharmacological action. Phytochemicals possess various health-related effects such as antimutagenic, antibacterial, antifungal, antithrombotic, anticarcinogenic and vasodilatory activities [2]. The ability to inhibit the growth of pathogenic microorganisms, without harming the host, demonstrates their potential application as therapeutic agents as well.

Cinnamomum tamala belonging to family "Lauraceae" is a widely used medicinal plant to treat various diseases. Its local name is Tezpat (Urdu). The leaves of this plant have also been extensively used extensively as spice in the foods industry due to its special aroma [3]. Cinnamomum tamala has been studied for its phytochemical constituents by different researchers. Prakash et al. [4] presented the result of the phytochemical analysis of the hexane, methanol, acetone and chloroform extracts of the Cinnamomum tamala leaves extracts. They detected alkaloid and tannins but didn't spot glycosides in there samples. Flavonoid were detected from methanol, acetone and chloroform extracts but were absent in hexane extracts. Sterol were detected from hexane, methanol and acetone but was not detected in chloroform extracts [4]. Similarly, Sukumar and his coworkers reported polyphenoles, flavonoids, tannins, alkaloids and saponins [5].
In Ayurvedic medicine Cinnamomum tamala were used in the treatment of diarrhea, anorexia, coryza and dryness of mouth. Cinnamomum tamala leaves are antihelminthic, diuretic and are good for spleen and lever as well as useful in inflammation. The medicinal uses also include as an antiflatulent, carminative and in the treatment of cardiac disorders [6]. Besides these, various pharmacological activities have been reported in natural products from cinnamomum species. The essential oil from Cinnamomum tamala exhibits antidermatophytic [7], antibacterial [8], antifungal, antihyperglycaemic and (antihypercholesterolanemic) effects [9].

At present, most of the drugs used in medicines are of synthetic origin. The emergence of drug resistant pathogens has created an alarming clinical situation in the successful treatment of microbial diseases. The pharmacological industry has produced a large number of new antibiotics but microorganisms resistance to these drugs has been increased, since as pathogens have genetic ability to acquire and transmit resistance to synthetic drugs that are being utilized as therapeutic agents [10]. The increase in the occurrence of multiple drug resistance has considerably slowed down the research and development of new synthetic antimicrobial drugs and has demanded the search for innovative antimicrobials from natural plant sources [11]. Such factors necessitated new research focusing on screening of natural products found in medicinally important plants to develop new and efficient drugs against microbial diseases and infections.

Medicinal plants may also contain significant quantities of some trace metals as they can easily be contaminated with heavy metals from the soil, water or air during their growth. Other sources of heavy metal contamination are dust, rainfall and fertilizers [12]. This contamination is one of the most serious environmental concerns due to the potential harmful effects of these toxic metals on human and animal health. Metals like $\mathrm{Zn}, \mathrm{Fe}, \mathrm{Cu}, \mathrm{Cr}$ and $\mathrm{Co}$ are toxic only at higher concentrations, while others like $\mathrm{Pb}, \mathrm{Hg}$ and $\mathrm{Cd}$ are fully toxic 
[13]. The consumption of heavy metal contaminated herbs may result in the accumulation of these metals in the human organs. Heavy metals above the permissible limit affect the human health and may result in sickness, mental retardation, high blood pressure, fatigue as well as kidney and brain disorders [14]. Therefore it is essential to determine and ascertain the levels of metallic contents in the medicinal plants as these elements induce toxic effects when consumed at higher levels.

Keeping in view the importance of natural antimicrobial agent which is a cheap source and eliminates many of the side effects associated with the synthetic antimicrobial drugs, the present study was designed to investigate the antimicrobial efficacy of Cinnamomum tamala. The presence of toxic or heavy metals may compromise the use of plant extract as therapeutic alternatives therefore atomic absorption photometer was used to quantitatively explore various essential or non-essential metals. Other biochemical tests were performed which helped in the evaluation of nutritional potential of this medicinal plant.

\section{Material and Methods}

\section{Chemicals}

Methanol, Iso-butanol, hexane, dichloromethane, chloroform, $\mathrm{FeCl}_{3}, \mathrm{H}_{2} \mathrm{SO}_{4}, \mathrm{CuSO}_{4}, \mathrm{NaOH}, \mathrm{HCl}$ and other reagents were of analytical grade and obtained from standard supplier and further verified by PCSIR laboratories complex Peshawar, Pakistan.

\section{Sample collection and identification}

The leaves of Cinnamomum tamala were obtained from Murree, Pakistan in February 2012. The plant was analyzed by specialists in Pakistan Council of Scientific and Industrial Research (PCSIR), Peshawar. The dried leaves of the plant were grinded by mortar and pestle and then stored in a dry place after packing in polythene bags for further extractions.

\section{Methanolic extract preparation}

The extract of Cinnamomum tamala was prepared in methanol. About $400 \mathrm{~g}$ of powdered plant was taken in a flat-bottomed flask and soaked in 1.4 liters of $80 \%$ methanol. The flask with its contents was packed and reserved for 3 days accompanying intermittent stirring and shaking. By Buchner funnel methanolic extract was filtered and with rotary evaporator (BUCHL rolavapour R-200) the filtrate was concentrated at bath temperature not exceeding $40^{\circ} \mathrm{C}$ to have sticky distillate of plant extract furnishing yield of $12.5 \%$ approximately.

\section{Phytochemical screening}

For the presence of secondary active metabolites like alkaloids, saponins, tannins, terpenoids, flavonoids and steroids in the selected plant leaves several chemical tests were performed $[15,16]$ while the ash content was found by following standard procedures [17].

\section{Metallic screening by atomic absorption spectrophotometer (AAS)}

Metallic content including calcium (Ca), iron (Fe), chromium (Cr), manganese $(\mathrm{Mn})$, lead $(\mathrm{Pb})$, copper $(\mathrm{Cu})$, sodium $(\mathrm{Na})$, potassium $(\mathrm{K})$, antimony $(\mathrm{Sb})$ and cadmium $(\mathrm{Cd})$ were determined by atomic absorption spectrophotometry.

\section{Antimicrobial assay}

Microorganism Collection and Maintenance: For antimicrobial activity three strains of gram positive bacteria i.e. Bacillus subtilis (BS), Bacillus atrophaeus (BA) and Staphylococcus aureus (S), six strains of gram-negative bacteria i.e. Escherichia coli (EC), Pseudomonas aeruginosa (PA), Salmoneella typhi (ST), Kleibsiella pneumonia (KP), Erwiniacarotovora Agrobacterium tumifaciens (EC) and (AT) and a fungal strain, Candida albicans (CA), were taken from the Center of Biotechnology and Microbiology, University of Peshawar, Peshawar, Pakistan. All the strains, before the subculture, were kept in MullerHinton Agar (MHA) at $4^{\circ} \mathrm{C}$ in the refrigerator.

Antibacterial assay of the Cinnamomum tamala against selected bacterial species: The tests for susceptibility were performed using modified Agar Well Diffusion Method [18] to examine the antibacterial activity of the Cinnamomum tamala leaves. The MHA was used as medium. The incubation temperature was fixed at $37^{\circ} \mathrm{C}$ and the culture was kept for 24 to 72 hours in triplicate. In a Petri-dish the broth culture $(0.6 \mathrm{~mL})$ of the test organism was taken. To this culture $20 \mathrm{~mL}$ of the sterile molten MHA was mixed. Wells were bored and added to the medium using Cinnamomum tamala leaves extract $(0.2 \mathrm{~mL})$. Inoculation was performed for one hour to ensure the strong diffusion of the antimicrobial agent to the medium. At $37^{\circ} \mathrm{C}$ the inoculation plates were incubated for 24 hours. The growth inhibition of microbes was calculated in millimeters [18].

Antifungal assay of the Cinnamomum tamala against selected fungal specie: The antifungal activity was evaluated by the Agar Well Diffusion Assay [16]. In DMSO (50 mg $/ 5 \mathrm{~mL}$ ) the plant extract was dissolved. In a test tube Sterile Sabouraud's dextrose agar medium (5 $\mathrm{mL})$ was placed and inoculated with the sample solution $(400 \mu \mathrm{g} / \mathrm{ml})$ kept in slanting position at room temperature overnight. On the slant the fungal culture was then inoculated. For 7 days the extracts were incubated at $29^{\circ} \mathrm{C}$ and the zone of inhibition of fungal growth was calculated [16].

\section{Results}

The solvent extractive values as a result of fractionation with nhexane, dichloromethane, isobutanol and water, found in percentage of plant material are shown in Table 1. The highest yield was recorded for n-hexane (2.44\%) followed by $2.4 \%$ for aqueous, $1.61 \%$ for Isobutanol and $0.63 \%$ for DCM extract.

\begin{tabular}{|l|l|l|l|l|l|l|l|}
\hline Plant & Plant material (gm) & Extract (gm) & \% age & $\begin{array}{l}\text { Hexane } \\
\text { (\% age) }\end{array}$ & $\begin{array}{l}\text { DCM } \\
\text { (\% age) }\end{array}$ & $\begin{array}{l}\text { Isobutanol } \\
\text { (\% age) }\end{array}$ & $\begin{array}{l}\text { Aqueous } \\
(\% \text { age) }\end{array}$ \\
\hline Cinnamomum tamala & 392.5 & 49.1 & 12.5 & 2.44 & 0.63 & 1.61 & 2.4 \\
\hline
\end{tabular}

Table 1: Extractive value of Cinnamomum tamala leaves in different solvents. 
Page 3 of 5

The results of qualitative phytochemical screening are summarized in Table 2 which shows that the methanolic extract of Cinnamomum tamala leaves is rich in phytonutrients like flavonoids, alkaloids, terpenoids and tannins. Saponins and Steroids were absent in the tested extracts.

\begin{tabular}{|l|l|l|l|l|l|l|}
\hline Plants & Alkaloids & Saponins & Flavonides & Steroids & Terpenoids & Tannins \\
\hline Cinnamomum tamala & $+\mathrm{ve}$ & $-\mathrm{ve}$ & $+\mathrm{ve}$ & $-\mathrm{ve}$ & $+\mathrm{ve}$ & $+\mathrm{ve}$ \\
\hline
\end{tabular}

Table 2: Qualitative analysis of phytochemicals in Cinnamomum tamala leaves.

In-vitro antimicrobial potential of Cinnamomum tamala leaves extracts were assessed by agar well diffusion method the result of which are illustrated in Table 3. All the evaluated extracts showed variable degree of inhibition zones against the selected six gramnegative, three gram-positive bacterial strains and a fungus. The plant extracts were significantly effective against most of the bacterial and fungus species however a few demonstrated the highest activity. All the extracts showed their best inhibitory activity against $B$. atropheous amongst which the aqueous extract recorded the highest zone of inhibition measuring $38 \mathrm{~mm}$. Crude, aqueous and DCM extracts were found completely inactive against $S$. Typhi. The crude extract showed its best activity against $B$. atropheous $(31 \mathrm{~mm}$ ) while found mildly active against $E$. coli $(10 \mathrm{~mm})$. In case of fungal activity, the DCM extract showed the highest zone of inhibition $(18 \mathrm{~mm})$ against $C$. albican while the least value $(12 \mathrm{~mm})$ was observed for both aqueous and crude extracts.

\begin{tabular}{|c|c|c|c|c|c|c|c|c|c|c|c|c|}
\hline \multirow{3}{*}{ Organism } & \multicolumn{10}{|c|}{ Zone of inhibition in $\mathrm{mm}$} & \multicolumn{2}{|l|}{ Antibiotics } \\
\hline & \multicolumn{2}{|c|}{ Hexane } & \multicolumn{2}{|c|}{ DCM } & \multicolumn{2}{|c|}{ Isobutanol } & \multicolumn{2}{|c|}{ Aqueous } & \multicolumn{2}{|c|}{ Crude extract } & Standard Drugs & Inhibition (mm) \\
\hline & $\begin{array}{l}6 \\
\mu \mathrm{l}\end{array}$ & $\begin{array}{l}12 \\
\mu \mathrm{l}\end{array}$ & $\begin{array}{l}6 \\
\mu l\end{array}$ & $\begin{array}{l}12 \\
\mu l\end{array}$ & $\begin{array}{l}6 \\
\mu l\end{array}$ & $\begin{array}{l}12 \\
\mu l\end{array}$ & $\begin{array}{l}6 \\
\mu l\end{array}$ & $\begin{array}{l}12 \\
\mu l\end{array}$ & $\begin{array}{l}6 \\
\mu l\end{array}$ & $\begin{array}{l}12 \\
\mu l\end{array}$ & & \\
\hline E.coli & 11 & 13 & 10 & 13 & 14 & 15 & 12 & 15 & 9 & 10 & Ciprofloxacin & 37 \\
\hline S.Typhi & 12 & 12 & Nil & Nil & 10 & 14 & Nil & Nil & Nil & Nil & Ciprofloxacin & 23 \\
\hline E.carotovora & 12 & 15 & 15 & 17 & 14 & 15 & 14 & 15 & 17 & 16 & Ciprofloxacin & 17 \\
\hline A.tumifaciens & 20 & 21 & 18 & 18 & 13 & 17 & 12 & 15 & 16 & 17 & Ciprofloxacin & 25 \\
\hline P.aeuroginosa & 23 & 24 & 17 & 20 & 17 & 20 & 17 & 19 & 21 & 22 & Ciprofloxacin & 34 \\
\hline K.pneumoniae & 23 & 25 & 20 & 21 & 18 & 20 & 17 & 22 & 13 & 18 & Ciprofloxacin & 29 \\
\hline S.aureus & 12 & 13 & 12 & 11 & 13 & 16 & 14 & 15 & 12 & 11 & Azithromycin & 21 \\
\hline B.subtilis & 15 & 14 & 16 & 17 & 16 & 19 & 13 & 15 & 14 & 16 & Azithromycin & 23 \\
\hline B.atropheous & 28 & 30 & 30 & 34 & 34 & 30 & 32 & 38 & 31 & 30 & Azithromycin & 27 \\
\hline C.albican & 16 & 17 & 18 & 18 & 15 & 16 & 12 & 13 & 12 & 15 & Clotrimazole & 32 \\
\hline
\end{tabular}

Table 3: Antimicrobial activity of Cinnamomum tamala.

Table 4 shows the findings of quantitative analysis of 10 metals including ( $\mathrm{Cd}, \mathrm{Mn}, \mathrm{Pb}, \mathrm{Cr}, \mathrm{Sb}, \mathrm{Cu}, \mathrm{Fe}, \mathrm{Ca}, \mathrm{Na}, \mathrm{K})$ determined by Atomic Absorption Spectrophotometer (AAS). The data revealed that the analyzed metals were present in different concentrations. The highest concentration of $\mathrm{Ca}(5634.25 \mathrm{mg} / \mathrm{kg})$ was recorded followed by $\mathrm{Na}(273.7 \mathrm{mg} / \mathrm{kg})$ and $\mathrm{Fe}(273.66 \mathrm{mg} / \mathrm{kg})$. The lowest concentration $0.322 \mathrm{mg} / \mathrm{kg}$ of $\mathrm{Pb}$ was found while $\mathrm{Cd}$ was not detected.

\section{Discussion}

The phytochemical analysis of the methanolic extract of Cinnamomum tamala leaves confirmed the presence of various secondary metabolites including alkaloids, flavonoids, terpenoids and tannins. This data is in accordance with the findings of Mishra et al. [1]. Phytochemicals are natural biologically active compounds that are known to possess physiological as well as medicinal properties.
Alkaloids show antihelminthic, antidiarrhoeal and antimicrobial activities [19]. They also acts as inhibitor, stimulator and growth terminator [20]. On the other hand, flavonoids exhibit antiviral, antioxidant and anti-inflammatory activities and are known to have anti malignant and anti-mutagenic effects. Moreover, flavonoids possess chemopreventive role in cancer through their effects on signal transduction in cell proliferation and angiogenesis [21], while tannins form a major group of phenolic compounds that act as primary antioxidants or free radical scavengers [22]. Like tannins, terpenoids also play an imperative role in antioxidant action as most natural antioxidative compounds often work synergistically with each other to create a broad spectrum of antioxidative actions that generates an operative defense system against free radical attack. Phytonutrients not only show antioxidant activity but also the antimicrobial ability of the plant is accredited to the presence of these chemicals. 


\begin{tabular}{|l|l|l|l|}
\hline Sr No. & Metals & Wavelength $(\mathbf{n m})$ & Results $(\mathbf{m g} / \mathbf{k g})$ \\
\hline 1 & $\mathrm{Cd}$ & 229 & $\mathrm{ND}$ \\
\hline 2 & $\mathrm{Mn}$ & 280 & 43.46 \\
\hline 3 & $\mathrm{~Pb}$ & 283.3 & 0.322 \\
\hline 4 & $\mathrm{Cr}$ & 359.3 & 1.127 \\
\hline 5 & $\mathrm{Sb}$ & 218 & 5.634 \\
\hline 6 & $\mathrm{Na}$ & Flame photometer & 273.7 \\
\hline 7 & $\mathrm{~K}$ & Flame photometer & 172.24 \\
\hline 8 & $\mathrm{Ca}$ & Flame photometer & 634.25 \\
\hline 9 & $\mathrm{Cu}$ & 325 & 8.048 \\
\hline 10 & $\mathrm{Fe}$ & 248.3 & 273.66 \\
\hline
\end{tabular}

also presents the permissible values of these elements together with the observed values.

The findings of this research clearly display the pharmacological importance of Cinnamomum tamala by identifying its potential medicinal prospective as possible drug source against the diseases caused by certain pathogens as well as diet supplement. However, further studies are required to more clearly understand the therapeutic values and curative effects of this plant.

\section{Conclusion}

Our results demonstrated the intense antimicrobial potential of Cinnamomum tamala leaves extracts against gram negative bacteria, gram positive and a fungus. The findings suggest that the plant could be regarded as promising alternative for development of efficient and effective drug from natural source that can be used for therapy of infectious diseases. The most active extracts could be subjected for further pharmacological evaluation by isolation of the therapeutic antimicrobials and further research on this plant can specify its

Table 4: Metallic screening of Cinnamomum tamala leaves using Atomic Absorption Spectrophotometer (AAS).

In present study, the antimicrobial action of the leaves of Cinnamomum tamala was found by different solvent extracts including $\mathrm{n}$-hexane, dichloromethane, water and isobutanol as well as crude extract, since the use of these solvents as extracting agents has been proved to be more efficient in extorting the active compounds [23]. All the extracts exhibited different degree of inhibition against selected gram positive and gram negative bacteria due to the fact that the methanolic extract of the plant comprises active compounds of varying polarity and solubility. The polarity of the antibacterial compounds makes them more readily extracted by organic solvents without negatively affecting the bio activity against bacterial species [24]. In our study, the extracts of Cinnamomum tamala leaves were tested for their antimicrobial efficacy and were found equally effective against gram positive and gram negative bacteria as shown in Table 3. All the evaluated extracts showed their best activity against B. Atropheous (gram-positive bacteria) and amongst them aqueous extract showed widest inhibition zone measuring $38 \mathrm{~mm}$ followed by $34 \mathrm{~mm}$ by isobutanol and dicholoromethane. The extracts were moderately effective against the fungus, $C$ albicans, recording inhibition zone in the range of $12-18 \mathrm{~mm}$.

Results of the mineral analysis are shown in Table 4 . The extract of the Cinnamomum tamala leaves contained negligible amount of other estimated heavy metals as compared to the concentration of $\mathrm{Ca}$ however $\mathrm{Na}, \mathrm{K}$ and $\mathrm{Fe}$ were found in minute concentration. Toxic elements like $\mathrm{Pb}$ were found in very insignificant amount. Our findings as a result of micronutrient analysis suggest that Cinnamomum tamala could play a very meaningful role in human nutrition as micronutrient source since essential minerals like $\mathrm{Ca}$ and $\mathrm{Fe}$ are necessary for human health. $\mathrm{Ca}$ is the main constituent of teeth and bones. It has also very important function in muscle contraction, neuro vascular transmission and blood coagulation [25]. Similarly, Fe being as essential constituent of hemoglobin facilitates the oxidation of proteins, carbohydrates and fats to controls the body weight. Low Fe content in humans causes myocardial infarction, gastro intestinal infection and nose bleeding [26]. In the introduction, potential hazards due to excess content of heavy metals in human body are mentioned. Although the discussion seems to imply that there was no excess content of heavy metals like $\mathrm{Fe}, \mathrm{Cd}$ etc. it would be better if the table

\section{Acknowledgment}

The financial support of higher education commission (HEC) Islamabad is cordially appreciated.

\section{References}

1. Mishra AK, Singh BK, Pandey AK (2010) In vitro-antibacterial activity and phytochemical profiles of Cinnamomum tamala (Tejpat) leaf extracts and oil. Reviews in Infection 1: 134-139.

2. Bidlack WR, Omaye ST, Meskin MS, Topham DK (2000) Phytochemicals as bioactive agents. CRC press.

3. Chang ST, Cheng SS (2002) Antitermitic activity of leaf essential oils and components from Cinnamomum osmophleum. J Agric Food Chem 50: 1389-1392.

4. Prakash (2014) Phytochemical analysis of Cinnamomum tamala of leaves extract. Indian Streams Research Journal 4: 1-3.

5. Dandapat S, Kumar M, Sinha MP (2014) Therapeutic efficacy of Cinnamomum tamala (Buch.-Ham.) and Aeglemarmelos (L.) leaf. Balneo Research Journal 5: 113-122.

6. Singh V, Gupta AK, Singh SP, Kumar A (2012) Direct analysis in real time by mass spectrometric technique for determining the variation in metabolite profiles of Cinnamomum tamalaNees and Eberm genotypes. The Scientific World Journal 2012: 549265.

7. Yadav P, Dubey NK, Joshi VK, Chansouria JPN, Yadav P (1999) Antidermatophytic activity of essential oil of Cinnamomum. Journal of Medicinal and Aromatic Plant Sciences 21: 347-351.

8. Goyal P, Chauhan A, Kaushik P (2009) Laboratory evaluation of crude extracts of Cinnamomum tamala for potential antibacterial activity. Electronic Journal of Biology 5: 75-79.

9. Srivastava B, Sagar A, Dubey NK (2011) Evaluation of Cinnamomum tamalaoil and its phenylpropanoideugenol for their antifungal and antiaflatoxigenic activity. Food Analytical Methods 4: 347-356.

10. Lopez A, Hudson JB, Towers GH (2001) Antiviral and antimicrobial activities of Colombian medicinal plants. J Ethnopharmacol 77: 189-196.

11. Pieboji JG, Eze N, Djintchui AN, Ngameni B, Tsabang N (2009) The invitro antimicrobial activity of some traditionally used medicinal plants against beta-lactam-resistant bacteria. J Infect Dev Ctries 3: 671-680.

12. Rahimi M, Farhadi R, Balashahri MS (2012) Effects of heavy metals on the medicinal plant. International journal of Agronomy and Plant Production 3: 154-158. 
Citation: Hassan W, Kazmi SNZ, Noreen H, Riaz A, Zaman B (2016) Antimicrobial Activity of Cinnamomum tamala Leaves. J Nutr Disorders Ther 6: 190. doi:10.4172/2161-0509.1000190

Page 5 of 5

13. Radojevic M, Bashkin VN (1999) Practical environmental analysis. Royal Society of Chemistry.

14. Hifsa M, Naeem I, Taskeen A, Zeb S (2009) Investigation of heavy metal in commercial spices brands. New York Science Journal 2: 1554-2200.

15. Sofowora A (1993) Medicinal plants and Traditional medicine in Africa. Spectrum Books Ltd, Ibadan, Nig.

16. Trease, Evans (2002) Pharmacognosy. International 15th edition saunder Edinburgh, New York.

17. Uddin G, Rauf A, Siddiqui BS, Shah SQ (2011) Preliminary comparative phytochemical screening of Diospyros lotus Stewart. Middle-East J Sci Res 10: 78-81.

18. Okeke MI, Iroegbu CU, Eze EN, Okoli AS, Esimone CO (2001) Evaluation of extracts of the root of Landolphia owerrience for antibacterial activity. J Ethnopharmacol 78: 119-127.

19. Prashant $\mathrm{T}$ (2001) Phytochemical screening and Extraction. International PharmaceuticaSciencia.

20. Abbass MN, Rana FA (2012) Chemical evaluation of weed seeds mixed with wheat grains at harvest. The journal of animal and plant sciences, 2012, 22: 283-288.
21. Saluja MS, Sangameshwaran B, Sharma A (2010) Cytotoxic activity of Cinnamomum tamala Linn. againstehrlich ascites carcinoma (EAC) in mice. The Pharma Research 3: 232-242.

22. Potterat O (1997) Antioxidants and free radical scavengers of natural origin. Current organic chemistry 1: 415-440.

23. Fazal H (2012) Selected medicinal plants used in Hebal industries; their toxicity against pathogenic microorganisms. Pak J Bot 44: 1103-1109.

24. Sanjay, Navneet (2010) Elements profile of traditional some important plants of Uttarakhand state, India. Report and Opinion 2: 34-36.

25. Khan SA, Khan L, Hussain I, Marwat KB, Akhtar N (2008) Profile of heavy metals in selected medicinal plants. Pakistan Journal of Weed Science Research 14: 101-110.

26. Dietary Reference Intakes (DRIs): Recommended Intakes for Individuals (PDF), Food and Nutrition Board, Institute of Medicine, National Academies, 2004, retrieved 2009-06-09. 